\title{
LA TRATA DE PERSONAS CON FINES DE EXPLOTACIÓN LABORAL Y TRABAJOS FORZADOS
}

\author{
Dr. Luis FERNANDo Ávila SALCEDo \\ Profesor e investigador del Instituto de \\ Investigaciones Jurídicas Facultad \\ de Derecho Universidad Anáhuac
}

\section{RESUMEN}

El presente artículo aborda la problemática de la trata de personas en dos de sus modalidades, la explotación laboral y el trabajo o servicios forzados como los efectos que, estos pudieran tener en el ámbito del derecho del trabajo y la seguridad social, formulados desde la configuración de una relación de trabajo, para lo cual se analiza la naturaleza jurídica de éste, sus características, la calidad de quien lo presta en cuanto persona y su dignidad, así como situaciones especiales que lo hacen más vulnerable en condición de migrante, para lo cual el marco constitucional en referencia, los derechos humanos y los criterios de la Organización Internacional del Trabajo resultan fundamentales para su entendimiento. Se plantea hipotéticamente para su ejercicio la creación de una jurisdicción especial para conocimiento simultáneo y resolución de la causa penal y laboral.

\section{Palabras clave:}

Explotación laboral, Trabajo como deber, Trabajo forzoso, Migración, Trabajo no es mercancía

\section{ABSTRACT}

This article addresses the problem of human trafficking in two of its forms, labor exploitation and forced labor or services as well as the effects that these might have in the field of labor law and social security, formulated from the configuration of a working relationship, analyzing its legal nature, its characteristics, the quality of the provider as a person and considering their dignity, as well as special 
circumstances that make them more vulnerable as migrant. The constitutional framework in reference, human rights and the criteria of the International Labor Organization are fundamental for its understanding. The creation of a special jurisdiction for simultaneous knowledge and resolution of criminal and labor cases is hypothetically considered

\section{Keywords:}

Labor exploitation, Work as duty, Forced labor, Migration, Labor is not merchandise

\section{INTRODUCCIÓN}

El desarrollo de las sociedades, el notorio avance que ha tenido la ciencia y la tecnología en la comprensión del universo, los diferentes procesos que en él ocurren, la relación de las personas con el mismo, han traído sin duda beneficios, contribuyendo a mejorar las condiciones de vida, tanto de sus miembros individualmente considerados, como en lo colectivo, no obstante el notorio desarrollo de las sociedades, se ha presentado contradictoriamente, un deterioro grave de los valores tradicionales, afectando la dignidad de la persona humana y siendo la trata de personas, una de esas manifestaciones negativas, de las que suele denominarse, la esclavitud de los nuevos tiempos.

En tal virtud, la situación plantea diversos problemas, atendibles desde perspectivas diferentes como disciplinas para su estudio, para el asunto que nos ocupa, y desde una aproximación legislativa, se presenta como plataforma de lanzamiento el tratamiento que, en particular dispone, la Ley General para prevenir, sancionar y erradicar los delitos en la materia de trata de personas y para la protección y asistencia a las víctimas de estos delitos, (LGPSDTPPAV), y en referencia particular al artículo décimo, cuyo texto es el siguiente:

"Toda acción u omisión dolosa de una o varias personas para captar, enganchar, transportar, transferir, retener, entregar, recibir, o alojar a una o varias personas para captar, enganchar, transportar, transferir, retener, entregar, recibir, o alojar a una o varias personas con fines de explotación se le impondrá de 5 a 15 años de prisión y de un mil a veinte mil días de multa, sin perjuicio de las sanciones que correspondan para cada uno de los delitos cometidos, previstos y sancionados en esta Ley y en los códigos penales correspondientes". ${ }^{1}$

La primera parte del artículo, establece las acciones que dan lugar a la trata de personas, así como las conductas en concreto, que realizan el acto punible, expresadas en ocho verbos, todos con fines de explotación, descrita seguidamente, en el artículo transcrito, de la siguiente manera:

"Se entenderá por explotación de una persona a:

I. La esclavitud, de conformidad con el artículo 11 de la presente Ley;

II. La condición de siervo, de conformidad con el artículo 12 de la presente Ley;

1 CÁMARA DE DIPUTADOS DEL HONORABLE CONGRESO DE LA UNIÓN, http://www.diputados.gob. mx/LeyesBiblio/pdf/LGPSEDMTP.pdf, CONSULTADA EL 23 DE AGOSTO DEL 2016. 
III. La prostitución ajena u otras formas de explotación sexual, en los términos de los artículos 13 a 20 de la presente Ley;

IV. La explotación laboral, en términos del artículo 21 de la presente Ley; (resaltado mío)

V. El trabajo o servicios forzados, en los términos del artículo 22 de la presente Ley; (resaltado mío)

VI. La mendicidad forzosa, en los términos del artículo 24 de la presente Ley;

VII. La utilización de personas menores de dieciocho años en actividades delictivas, en los términos del artículo 25 de la presente Ley;

VIII. La adopción ilegal de persona menor de dieciocho años, en los términos de los artículos 26 y 27 de la presente Ley;

IX. El matrimonio forzoso o servil, en los términos del artículo 28 de la presente Ley, así como la situación prevista en el artículo 29;

$\mathrm{X}$. Tráfico de órganos, tejidos y células de seres humanos vivos, en los términos del artículo 30 de la presente Ley; y

XI. Experimentación biomédica ilícita en seres humanos, en los términos del artículo 31 de la presente Ley".2

El propósito del presente estudio, es vincular en la decisión que sanciona, la conducta delictiva de trata de personas, efectos laborales y de seguridad social en particular, los que hacen referencia a las fracciones IV y V, concerniente a la explotación laboral y el trabajo o servicios forzados, presentando las siguientes consideraciones:

\section{EXPLOTACIÓN LABORAL}

Respecto de la explotación laboral el artículo 21 de la Ley (LGPSDTPPAV), en estudio preceptúa:

"Será sancionado con pena de 3 a 10 años de prisión, y de 5 mil a 50 mil días multa, quien explote laboralmente a una o más personas.

Existe explotación laboral cuando una persona obtiene, directa o indirectamente, beneficio injustificable, económico o de otra índole, de manera ilícita, mediante el trabajo ajeno, sometiendo a la persona a prácticas que atenten contra su dignidad, tales como:

I. Condiciones peligrosas o insalubres, sin las protecciones necesarias de acuerdo a la legislación laboral o las normas existentes para el desarrollo de una actividad $\mathrm{o}$ industria;

II. Existencia de una manifiesta desproporción entre la cantidad de trabajo realizado y el pago efectuado por ello, o

III. Salario por debajo de lo legalmente establecido". ${ }^{3}$

\section{Comentario:}

Para diferenciar las conductas que someten a una persona a explotación laboral, de aquellos trabajos calificados como obligatorios, el artículo 23 prescribe lo siguiente:

$\begin{array}{ll}2 & \text { Ídem. } \\ 3 & \text { Ídem. }\end{array}$ 
"I. Se exija en virtud de las leyes sobre el servicio militar obligatorio;

II. Forme parte de las obligaciones cívicas normales de los ciudadanos hacia la Federación, el Distrito Federal (Hoy Ciudad de México) o sus demarcaciones territoriales, los estados o municipios;

III. Se exija a una persona en virtud de una condena pronunciada por sentencia judicial, o en los términos del artículo 21 Constitucional como trabajo a favor de la comunidad, a condición de que este trabajo o servicio se realice bajo la vigilancia y control de las autoridades públicas, y que dicha persona no sea cedida o puesta a disposición de particulares, compañías o personas jurídicas de carácter privado;

IV. Los trabajos sean voluntarios y realizados por integrantes de una comunidad en beneficio directo de la misma y, por consiguiente pueden considerarse como obligaciones cívicas normales que incumben a los miembros de la comunidad local, nacional o a una organización internacional, a grupos o asociaciones de la sociedad civil e instituciones de beneficencia pública o privada". ${ }^{4}$

La situación nos presenta el siguiente cuestionamiento. Tratándose de explotación laboral, se puede configurar una relación de trabajo, la conducta se circunscribe únicamente al ámbito de lo punible, la víctima desde la perspectiva jurídica se encuentra indefensa ante su realidad como trabajador. Ante una posible negativa, se presenta paradójico en una época en que intelectuales, filósofos, escuelas de pensamiento entre otras, han considerado la importancia social del trabajo, expidiéndose leyes que buscan su protección, sin embargo, la vinculación que hipotéticamente se plantea se difumina cuando se trata de explotación laboral.

Para entender las causas que dan lugar a la trata de personas, investigaciones sostienen que su origen se cifra en conductas sociales pre-existentes, por lo general, toleradas por la sociedad o vistas por las autoridades con discrecionalidad cuyo desarrollo va generando a su vez pautas para otras manifestaciones nocivas que, como lo explica el profesor Rodolfo Casillas: “... la pre existencia de los mercados del sexo dieron lugar a la trata de personas con finalidad de explotación sexual, a la vez que la existencia de esos mismos mercados permite obnubilar esa trata para el ojo no especializado". ${ }^{5}$

La misma indiferencia o aquiescencia de las sociedades han hecho de actividades socialmente nocivas, para la persona y su dignidad sean vistas al amparo de la discrecionalidad de autoridades, como expresión de su libertad, sin ir más allá de las consecuencias que se producen en detrimento de quien lo padece además de presentarse como una manifiesta injusticia. La trata de personas como categoría genérica, presenta una diversidad de modalidades de las cuales se pueden enumerar 12 formas, y precisadas por Denisse Velázquez Galarza así: 1) "La trata con fin de explotación sexual, que muchas veces puede resultar la más visible, pero no es la única; 2) la esclavitud; 3) la explotación laboral (resaltado mío); 4) los trabajos y servicios forzados (resaltado mío); 5) la servidumbre

\footnotetext{
Ídem.
}

5 RODOLFO CASILlAS RAMÍREZ, "Conocimiento Social, Derechos Humanos y Trata de Personas en México", en, Análisis sobre la trata de personas, No. 14, Estudios judiciales TSJDF, México, 2014, p. 23. 
por deudas; 6) la servidumbre por gleba; 7) el tráfico ilegal de órganos, tejidos o células de seres humanos vivos; 8) matrimonios forzosos o serviles; 9) mendicidad forzada; 10) experimentación biomédica ilícita en seres humanos vivos, que es una nueva modalidad que se incluye en esta legislación; 11) adopciones ilegales, y 12) la utilización de persona menores de 18 años para actividades delictivas". ${ }^{6}$

\section{TRABAJO O SERVICIOS FORZADOS}

En referencia al trabajo o servicio forzados, la ley en estudio remite al artículo 22, precepto que señala al respecto:

"Será sancionado con pena de 10 a 20 años de prisión, y de 5 mil a 50 mil días multa, quien tenga o mantenga a una persona en trabajos forzados.

Hay trabajo forzado cuando el mismo se obtiene mediante:

I. Uso de la fuerza, la amenaza de la fuerza, coerción física, o amenazas de coerción física a esa persona o a otra persona, o bien utilizando la fuerza o la amenaza de la fuerza de una organización criminal;

II. Daño grave o amenaza de daño grave a esa persona que la ponga en condiciones de vulnerabilidad;

III. El abuso o amenaza de la denuncia ante las autoridades de su situación migratoria irregular en el país o de cualquier otro abuso en la utilización de la ley o proceso legal, que provoca que el sujeto pasivo se someta a condiciones injustas o que atenten contra su dignidad".

Los dos aspectos que ocupan la atención del presente estudio, la explotación laboral, los trabajos y servicios forzados, han tenido mayor relevancia en el ámbito de lo penal, acreditado el delito, el responsable purgará la pena correspondiente.

El aspecto fáctico de la conducta, tiene de manera implícita, una situación objetiva, que manifiesta la energía de trabajo, si bien bajo condiciones extraordinarias, no deja de considerarse como trabajo, siendo, así las cosas, la premisa que permita incorporar, los efectos de una relación de trabajo a situaciones cuya causa radica en un delito, como los expuestos, pueden ser justificados desde la perspectiva del trabajo y del trabajador establecidos en la Constitución, en la Declaración de los Derechos Sociales y una de sus leyes reglamentarias, la Ley Federal del Trabajo.

\section{PERSPECTIVA JURÍDICA DEL TRABAJO}

Uno de los aspectos generales considerados para entender el trabajo dentro del contexto jurídico, es la dimensión que éste adquiere, en cuanto se predica del ser humano, exteriorizada de manera cualificada en la denominada energía de trabajo.

En este sentido la relevancia del trabajo y su connotación en la sociedad, tiene jurídicamente un significado profundo como se expresa en el artículo 123

6 DENISSE VELÁZQUEZ GALARZA, “La trata de personas desde la perspectiva internacional”, en Análisis sobre la trata de personas, No. 14, Estudios judiciales TSJDF, México, 2014, p. 13. 
constitucional, presentándolo como del más alto nivel jerárquico, del cual se desprende una especial protección del trabajador y del trabajo, en consecuencia, los derechos que le asisten, los cuales vistos en conjunto tiene por objetivo garantizar el equilibrio entre los factores de la producción.

La perspectiva jurídica de trabajo, consagrado en el artículo $3^{\circ}$ de la Ley Federal del Trabajo, es la siguiente:

"El trabajo es un derecho y un deber sociales. No es artículo de comercio".

\section{Veamos:}

\section{1 trabajo es un derecho}

Establecer al trabajo, como un derecho, no se refiere al señalamiento de una acción judicial en concreto con la que pueda exigirse de las autoridades correspondientes, se proporcione uno a quien demanda, como si se tratara, por ejemplo, de la acción de reinstalación.

Entonces, ¿cómo debe entenderse ese derecho? Para dar respuesta al interrogante planteado, se debe remitir, a la propia organización política que regula a la sociedad en su conjunto, al Estado, en cuyo caso se precisa fijar los fines que, históricamente justifican su existencia como el papel real, que juega en las sociedades contemporáneas.

En este sentido se advierte que el Estado, cuyo objetivo fundamental es lograr el bienestar común, aglutinará todos los elementos que promuevan una plataforma que, funcione como soporte, en la generación de una infraestructura que de posibilidades de acceso al trabajo, así las cosas el Derecho al Trabajo, se consolida de la mano con el Estado y los medios que lo propician, para entender así, que las diversas acciones que éste acomete, con los diversos sectores de la producción, en la generación de los empleos que la sociedad demanda, son constitutivos de una naturaleza, sobre la cual descansa la solidez y buen funcionamiento del mismo, como creador de trabajo, consiguientemente de oportunidades.

\section{Antecedentes art. tercero LFT}

Igualmente resulta importante la explicación de los antecedentes del artículo $3^{\circ}$ señalados por el Mtro. Néstor de Buen, de la siguiente manera:

"Es interesante descubrir los antecedentes del art. $3^{\circ}$ que los tiene, directos, en la Carta de la Organización de los Estados Americanos, aprobada en Bogotá [...] De la Cueva, miembro de la delegación mexicana fue quien propuso el texto del artículo 29 b) en el que se señala: "El trabajo es un derecho y un deber social; no será considerado como un artículo de comercio: reclama respeto para la libertad de asociación y la dignidad de quien lo presta y ha de efectuarse en condiciones que aseguren la vida, la salud y un nivel económico decoroso, tanto en los años de trabajo, como en la vejez o cuando cualquier circunstancia prive al hombre de la posibilidad de trabajar". Este pacto fue ratificado por nuestro país el 23 de noviembre de 1948, por decreto publicado en el DOF de enero de 1949". ${ }^{7}$

7 NÉSTOR DE BUEN L., Derecho del trabajo, T.I., vigésima primera edición, Edit. Porrúa, México, 2013, p. 61. 
La construcción jurídica del derecho del trabajo, se precisa en los medios que la organización política provea, a las personas bajo su soberanía, accediendo a la actividad productiva de la misma, mediante el trabajo, cuyos mecanismos en su realización, se encuentran sujetos a las propias condiciones tanto, sociales, políticas y económicas, por lo mismo puede en esencia, ser un principio y una meta que, permitiría la consecución de los propios fines del Estado, como es el bienestar común.

En la doctrina se encuentran enseñanzas que se desprenden de este principio, cuya integración en la Ley Federal del Trabajo y de manera particular en la denominada estabilidad en el empleo, cuando un trabajador es despedido, sin causa justificada, tiene el Derecho a la reinstalación, en el discernimiento que, la acción correspondiente, ordena permanecer en el empleo, dimensión jurídica cuyo plano lo coloca por encima del interés personal, por lo mismo, supeditado en función del derecho en estudio, en cuanto se presenta un interés superior.

Reforzando el planteamiento anterior, en situaciones similares como, de los derechos de preferencia, antigüedad y ascenso, en cuyo caso el o los trabajadores aspiran a un puesto vacante o de nueva creación, el tiempo acumulado laboralmente hablando, tiene una cualificación especial que, de no respetarse, el trabajador tiene derecho a solicitar ante la Junta de Conciliación y Arbitraje, que se le otorgue el puesto correspondiente o se le indemnice, mandato que al igual del ejemplo anterior, trasciende el interés particular.

\subsection{Trabajo como deber}

Como correlativo al derecho del trabajo, se encuentra el deber al trabajo, cuya esencia radica en la respuesta que, la sociedad espera de sus integrantes en cuanto ocupar su energía de trabajo en actividades con fines productivos, con proyección de beneficio propio y hacia los demás, fincado en el decoro de sus acciones que la persona fundamenta y proyecta.

El Mtro. Mario de la Cueva, hace mención de los aspectos formulados en la IX Conferencia Internacional Americana, realizada en Bogotá 1948, que en aparte pertinente señala:

"Como resultado de esta que podría denominarse una concepción solidarista de la vida orientada a la justicia social, la fórmula de Bogotá y del artículo tercero de la Ley podría parafrasearse diciendo que la sociedad tiene el deber de crear las condiciones que permitan al hombre cumplir su deber de trabajar". ${ }^{8}$

Se precisa entonces la iniciativa al cumplimiento, con los elementos que la sociedad le brinda, para ser desarrollados mediante el trabajo, fortaleciendo los vínculos con los fines que, en general pueda tener la sociedad, cuya correlación de fuerzas, permita la construcción de un sano tejido social.

8 MARIO DE LA CUEVA, El Nuevo Derecho del Trabajo Mexicano, T.I., $7^{\mathrm{a}}$ edición, Edit. Porrúa, México, 1981, p. 108. 
Uno de los factores que corresponde a la esencia del Nuevo Derecho del Trabajo, además de los señalados, como derecho y deber, es el tratamiento que jurídicamente se desprende de la relación de trabajo, en cuanto al acuerdo de voluntades para la prestación de un servicio personal, subordinado que, tratándose de un negocio jurídico con características especiales, se sustrae de la esfera mercantil, o civil propiamente dichas, siendo la energía de trabajo emanación de un sujeto cualificado, el trabajador, cuya realización se encuentra dentro del marco de la subordinación y cuya condición, no asume el carácter de cosa, como cuando se realiza un contrato de compraventa, respecto de productos que, satisfacen necesidades personales, el vestido, la comida, etc.

Existe entonces una condición cualificada del trabajo por emanar del ser humano, cuyo ejercicio involucra diversos aspectos:

4.1 El personal: como factor de realización en cuanto le permite una ubicación de desarrollo, respecto sus conocimientos, capacidades, facultades que materializa en la realización de productos, servicios, entre otras, las misma implica una relación con su propia existencia que, el trabajo edifica, en tanto su acción desdobla, diversas posibilidades conduciéndole al sentimiento de sentirse útil, en este sentido se construye una dinámica tal cuyo movimiento experimenta vitalidad, impulso de empezar y continuar por el loable fin del trabajo.

4.2 Proyección externa: Siempre que se habla de trabajador, se le vincula con acciones que, trasciende las fronteras de lo personal, y es la proyección hacia los que dependen económicamente, fruto de la construcción de lazos como la familia, cuya guarda y protección, implica una serie de procesos que relacionados con el trabajo, pueden ser consistentes en la medida que respalde los satisfactores propios de la vida, la alimentación, el vestido, la salud que, siendo necesarios, encuentra respaldo en el trabajo y sus frutos como sería el salario, el medio para proveerlos, en la cantidad y calidad suficientes, que le brindan libertad y autonomía necesarias.

4.3. Relación con la empresa: Tratándose de una unidad de producción la articulación y coordinación de los diversos componentes conducen a la realización del objetivo u objetivos trazados, de tal manera que la incorporación del trabajo y su entendimiento con quien lo dirige y administra requiere de sinergias que permitan un correcto ajuste con los propósitos de la misma.

En este sentido el trabajo tiene una función fundamental en la integración con el capital, para fortalecimiento de la empresa y todos sus componentes, la retribución del trabajo en cantidad y calidad contribuye al fortalecimiento del trabajador individualmente considerado, como de los que de él dependen económicamente, de ahí la importancia que, en las sociedades contemporáneas, adquiere el derecho social, accionante de los aspectos retributivos del trabajo. 
4.4 Proyección a la seguridad social: dentro de los sistemas jurídicos laborales, la protección al trabajo ha tenido en la subordinación, el elemento central de la relación de trabajo, situación que genera automáticamente, derechos como los de seguridad social, formalizada a través de la afiliación a una entidad de seguros sociales. De los mismos deviene un conjunto de prestaciones tanto asistenciales como económicas, orientados al restablecimiento o mantenerse como soporte frente a la eventualidad de la contingencia social.

El beneficio del seguro social trasciende lo personal, en cuanto también cubre a los adscritos, es decir familiares, (cónyuge, compañera permanente, hijos) o en el peor de los escenarios, su fallecimiento, cuya proyección tiene en la pensión, una evidencia relevante. Así las cosas, es el trabajo en condición de subordinación detonante de la protección en estudio.

4.5 Dignidad humana: la afirmación de que el trabajo dignifica a la persona humana puede colegirse de la siguiente reflexión:

"Por ello, si bien a priori se puede partir de una idea general de la dignidad humana, como concepción del hombre en tanto persona, en la cual se corporeizan los más altos valores espirituales y costumbres éticas, individuales y comunitarias, constituyendo un principio y un límite de la actuación de todas las personas, la sociedad y del Estado; ...". 9

La condición de persona trae inherente la de dignidad, es decir ésta es intrínseca, por lo que se predica la igualdad por naturaleza entre los hombres. En tal virtud cada individuo posee una misma dignidad natural, por lo tanto: "Ello impide reducir su valor a diversos factores: su pertenencia a un Estado, su posición social, su eficacia o su producción, etc. Esta visión personalista permite sentar las bases para superar tanto el reduccionismo aristotélico como el pragmatismo moderno". ${ }^{10}$

Esto implica que el desarrollo del trabajo y la dignidad de quien lo realiza, se funde en una sola, cuyo resultado permite con precisión diferenciarlo, del trabajo que realiza una máquina, de la cual se predica automatismo, carente de voluntad, menos ser trascendente, como sí se afirma del trabajo humano, desempeño que, representa para la persona, su propio perfeccionamiento, permitiéndole transformar la naturaleza, en tal sentido el trabajo debe estar al servicio del hombre y no de manera contraria.

La dimensión de la dignidad humana de la persona, de frente al trabajo, coloca a su vez al Estado en una postura orientada a su reconocimiento como, la instauración de medios que, apuntan a su protección, propio de un Estado de Derecho, por lo mismo toda acción u omisión que vulnera la dignidad de la persona, se traduce en su antítesis, tal consideración se convierte en factor de medición de

9 CÉSAR LANDA, "Dignidad de la Persona Humana”, Revista del IIJ, Cuestiones Constitucionales Revista Mexicana de Derecho Constitucional, No. 7, julio-diciembre 2002 en, https://revistas.juridicas.unam.mx/index. $\mathrm{php} /$ cuestiones-constitucionales/article/view/5649/7378, consultada el 10 de noviembre del 2016

10 ANGELA APARISI MIRALLES, Ética y Deontología para Juristas, Edit. Porrúa, México, 2009, p.20. 
la realidad, resultado de la aplicación de la dignidad humana, al trabajo, por lo mismo se traduce en un índice positivo, la proscripción del ejercicio de violencia física o moral, en la libertad para la realización del trabajo.

La sustracción del Estado en la aplicación de la ley frente a conductas que cosifican, degradan, mercantilizan al ser humano, se ha convertido en uno de los peores lastres que, la humanidad en pleno "desarrollo" viene viviendo, bajo la égida de intereses mezquinos que, reflejan el retroceso de grupos humanos, ante la fragilidad de los valores que buscan acomodo en las sociedades de consumo, sometidos al control de lo económico.

Reivindicar la razón de la dignidad humana, es una tarea que atrae en su acción a todos los que forman parte de un Estado y el Estado como autoridad, facultado para garantizar su protección, utilizando todos los medios que conduzcan a su prevalencia.

\subsection{Responsabilidades y sanciones desde la perspectiva laboral}

La relación inmediata con conductas avocadas a quien padece la explotación laboral, es el tratamiento de naturaleza penal que, como ha quedado expuesto, no obstante, la comisión de un delito, se plantea efectos hacia otras disciplinas jurídicas, como la laboral, en tanto la existencia de hecho, de una relación de trabajo, cuya afirmación pone de manifiesto la aplicación del ordenamiento jurídico conducente, la Ley Federal del Trabajo, que ante su vulneración, prescribe la obligatoriedad de denunciar, tal como lo señala el artículo 1003 así:

"Los trabajadores, los patrones, y los sindicatos, federaciones y confederaciones de unos y otros, podrán denunciar ante las autoridades del trabajo las violaciones a las normas de trabajo.

(R) Los presidentes de las Juntas Especiales y los Inspectores de Trabajo, tienen la obligación de denunciar al Ministerio Público al patrón de una negociación industrial, agrícola, minera, comercial o de servicios que haya dejado de pagar o pague a sus trabajadores cantidades inferiores a las señaladas como salario mínimo general. (DOF 30/11/12)"

La situación fáctica que, presenta la explotación laboral, demanda criterios más allá de los estrictamente penales, en cuanto se evidencia simultáneamente, aspectos considerados en el ámbito de lo laboral, partiendo de la existencia de una relación de trabajo, cuya naturaleza informal, se configura con la existencia de, cuando menos dos elementos, la prestación de un servicio personal y la subordinación que en tratándose, de la explotación laboral o el trabajo o servicio forzados, es una situación inmanente que como ya se explicó en una situación de normalidad surgen de inmediato otros derechos, como los de seguridad social. Lo que sucede entonces con la víctima de estos delitos, es la sanción de los mismos, sin ninguna consecuencia por lo que corresponde al trabajo. Hay personas que han sido años víctima de este delito que, en el caso de ser visualizada de manera integrada, la exigencia de un salario remunerador y el fincamiento de capitales constitutivos, por no afiliación al seguro social, más la consideración de semanas 
dejadas de cotizar, permitiría resarcir en la medida de lo posible, las consecuencias nocivas de quien brindo su energía de trabajo, bajo condiciones que vulneran su libertad.

\section{¿Cuál es el sentido?}

Establecer ante la existencia de la explotación laboral y el trabajo o servicio forzados, una relación de trabajo, en consecuencia, le sean aplicados todos los derechos que devienen, la fijación del salario, la vinculación al seguro social, como el reconocimiento de semanas cotizadas, lo que le dejaría en la posibilidad de obtener una pensión, en cualquiera de los ramos del seguro social obligatorio, situación que en la actualidad no se tiene previsto en la legislación, tropezando especialmente con factores como los de competencia, en tanto un juez de lo penal, no asumiría el conocimiento de una causa laboral y viceversa.

Esto invita a un planteamiento, inclusive constitucional, para determinar una competencia ampliada, frente a situaciones del impacto como los estudiados, o para establecer de oficio, la acción bien de lo penal a lo civil o viceversa para llevar las causas en paralelo, para obtener los efectos jurídicos y las consecuencias que de las dos causas se desprendan.

\section{MIGRACIÓN Y AFECTACIÓN A LOS DERECHOS HUMANOS}

Fenómeno propio de nuestra época es la migración, cuyas causas multifactoriales, enfatizando en aquéllas motivadas por las condiciones que, en sus países de origen pone en riesgo su vida, o integridad, viéndose obligados a trasladarse a diferentes destinos, situación que en el mejor de los casos, los coloca en calidad de personas indocumentadas, con los efectos contraproducentes que dicha situación genera, en tanto el desamparo jurídico, aunado al rechazo de los habitantes receptores, cuya situación amerita respuestas más allá de las acciones que invitan a la expulsión del territorio. Al respecto resulta pertinente el tratamiento que la OIT, realiza de la materia en cuestión:

“Los dos Convenios sobre el trabajo forzoso de la Organización Internacional del Trabajo, a saber, el Convenio sobre el Trabajo Forzoso de 1930 (Núm. 29) y el Convenio sobre la abolición del trabajo forzoso, 1957 (núm. 105) son dos de los instrumentos más ampliamente ratificados. Sin embargo, esos problemas se siguen dando a escala alarmante, y afectan a todas las regiones del mundo de forma diversa y en distinto grado". ${ }^{11}$

Si bien tanto la iniciativa de la OIT, orienta su acción a la eliminación del trabajo forzoso, las estadísticas que la misma nos presenta para el año 2014 son las siguientes:

11 ORGANIZACIÓN INTERNACIONAL DEL TRABAJO, "Los trabajadores migrantes no son una mercancía”. La revista de la OIT, número especial de 2014, publicada por el Departamento de Comunicación e Información Pública de la Organización Internacional del Trabajo (OIT), Ginebra, 2014, p.14. 
"al menos 20,9 millones de personas son víctimas del trabajo forzoso en todo el mundo;

si bien la Región de Asia y el Pacífico cuenta con el mayor número de víctimas en términos absolutos - 11,7 millones - el trabajo forzoso afecta a todas las regiones del mundo, y probablemente a todos los países; [...] las mujeres y las niñas son las más afectadas (11,4 millones), pero no mucho más que los hombres y los niños $(9,5$ millones de víctimas); una cuarta parte (5,5 millones) de todas las víctimas son menores de 18 años; el 90 por ciento del trabajo forzoso se da en la "economía privada". De este porcentaje, tres cuartas partes se concentran en actividades productivas como la agricultura, el trabajo doméstico, la construcción, la pesca y la fabricación, y el resto en actividades de explotación sexual con fines comerciales. Alrededor del 44 por ciento de las víctimas (9,1 millones) emigraron dentro de un país o de un país a otro antes de ser explotadas". ${ }^{2}$

La estadística anterior establece un número significativo, de afectados por sometimiento a trabajo forzoso, en actividades económicas, donde tradicionalmente, las condiciones han sido desfavorables en el orden nacional y si al mismo agregamos la condición de migrante que busca ocuparse en esas actividades, los coloca en una condición mayor de desprotección. Continuando con el estudio realizado por la OIT, expresa lo siguiente:

"La situación real de los trabajadores migrantes y el respeto de sus derechos, independientemente de la percepción que se tenga de ello, suscita con frecuencia una gran inquietud. Las denuncias de abusos graves y discriminación de los trabajadores migrantes son demasiado frecuentes, en particular sobre prácticas de contratación no éticas y salarios impagados, violencia y condiciones de trabajo inaceptables. En ciertos casos, la migración laboral va a la par con el tráfico de personas o el trabajo forzado". ${ }^{13}$

La Combinación de migración en condición de indocumentado, la labilidad de los sistemas jurídicos, dejan en condición de indefensión a la persona que resulta ser factor de aprovechamiento por grupos de delincuentes, cuya coacción sumado a la no protección jurídica coloca a las personas como víctimas, de un negocio inescrupuloso, aumentando su vulnerabilidad, y en sujeto de explotación de los tratantes.

\section{Veamos:}

Las condiciones bajo las cuales una persona se ve sometida a trabajar, en tanto peligrosas o insalubres en el "mejor" de los casos, con afección directa al decoro en su calidad de persona, menoscabando su dignidad, fácticamente, ejecuta un trabajo, exteriorizado en su energía, cuyas condiciones anormales se presentan en función de la desviación del objetivo de la subordinación, la acción que acomete se desarrolla en términos de extralimitación de la situación objetiva formada normalmente entre el trabajador y empleador, componente que no anula,

13 Ibidem, p.16. 
el argumento de dar origen a una relación de trabajo y que de existir duda, deberá acogerse en beneficio, de su interpretación, la máxima de indubio pro operarium.

La situación evidencia, el desamparo que la explotación laboral y el trabajo o servicios presenta desde la perspectiva laboral, aunado al rigor jurídico del conocimiento de la autoridad por materia, en sentido de la hipótesis es generar una actuación de la autoridad asumiendo las dos causas, lo que para ojos del experto, dentro del ordenamiento jurídico vigente no tiene posibilidades, pero ante la evidencia de los efectos que produce en el corto y mediano plano, las conductas criminales descritas, debe formularse una solución jurídica, vía reforma constitucional, vía leyes reglamentarias para que pueda, posiblemente en una jurisdicción especial asumir el conocimiento de las dos causa, acumulando procesos o atrayéndolos, para resolver en una instancia lo concerniente a la causa penal como la laboral.

La calificación de víctima (sujeto pasivo del delito)-trabajador, impulsaría el marco teórico del contrato realidad de la esfera laboral, incidiendo de manera relevante en la política de atención a víctimas, recuperando en la medida de lo posible aspectos que al día de hoy no le son reconocidos como son los derechos laborales y de seguridad social.

La visión trasversal del problema podría contribuir en gran medida a enervar los efectos nocivos de quien o quienes transcurrieron una parte de su vida sojuzgados, tiempo irreversible e imposible de recupera, por tal razón, el mecanismo planteado podría en parte resarcir, los daños y afectaciones de emplear su energía de trabajo bajo condiciones de coacción física o moral.

La pretensión del presente estudio, es atraer la atención de expertos, para continuar con propuestas que pueda atacar el problema de fondo y que el derecho sea un instrumento eficaz para brindar una solución, que se demanda pronto y expedita ante conductas fraguadas por la codicia y maledicencia del propio ser humano. La sanción penal no es definitivamente la única solución al problema, la propuesta es extenderlo al campo laboral y de la seguridad social y hacer frente desde el derecho a un problema que, desafortunadamente va cobrando día con día más víctimas.

Desde luego aquellas personas que actúan al margen de la ley, acuden a todos los mecanismos para que su conducta no pueda ser descubierta, por lo que se hace necesaria, la participación activa de las autoridades laborales, en actividades económicas que las investigaciones, señala como proclives a la comisión de faltas al ordenamiento laboral, empleando al máximo sus facultades para hacer que se cumplan las leyes, denunciando, previniendo etc., muchas de las veces la inactividad o displicencia de las mismas, son también la causa del problema, favoreciendo conductas que atentan contra el más elemental de los derechos del ser humano, su dignidad.

La Constitución Política de los Estados Unidos Mexicanos bajo la égida de la protección de la persona humana, se precisan en los derechos humanos, y tienen desarrollo en un sistema jurídico donde el Estado orientan sus acciones, a hacer prevalecer la persona, frente a las acciones que la ponen en tela de juicio o factores que la vulneran, razón por la cual los derechos humanos se suman, a 
las disciplinas que analizan la protección y salvaguarda de la misma, contra todo acto u omisión que laceran su condición, la explotación laboral y trabajo o servicio forzoso lo es. En este sentido puede entenderse, el artículo 1 de la CPEUM, cuyo contenido es el siguiente:

\section{Denominación del Capitulo reformada DOF 10-06-2011}

"En los Estados Unidos Mexicanos todas las personas gozarán de los derechos humanos reconocidos en esta Constitución y en los tratados internacionales de los que el Estado Mexicano sea parte, así como de las garantías para su protección, cuyo ejercicio no podrá restringirse ni suspenderse, salvo en los casos y bajo las condiciones que esta Constitución establece.

\section{Párrafo reformado DOF 10-06-2011}

Las normas relativas a los derechos humanos se interpretarán de conformidad con esta Constitución y con los tratados internacionales de la materia favoreciendo en todo tiempo a las personas la protección más amplia.

\section{Párrafo adicionado DOF 10-06-2011}

Todas las autoridades, en el ámbito de sus competencias, tienen la obligación de promover, respetar, proteger y garantizar los derechos humanos de conformidad con los principios de universalidad, interdependencia, indivisibilidad y progresividad. En consecuencia, el Estado deberá prevenir, investigar, sancionar y reparar las violaciones a los derechos humanos, en los términos que establezca la ley.

Párrafo adicionado DOF 10-06-2011

Está prohibida la esclavitud en los Estados Unidos Mexicanos. Los esclavos del extranjero que entren al territorio nacional alcanzarán, por este solo hecho, su libertad y la protección de las leyes.

Queda prohibida toda discriminación motivada por origen étnico o nacional, el género, la edad, las discapacidades, la condición social, las condiciones de salud, la religión, las opiniones, las preferencias sexuales, el estado civil o cualquier otra que atente contra la dignidad humana y tenga por objeto anular o menoscabar los derechos y libertades de las personas.

Párrafo reformado DOF 04-12-2006, 10-06-2011

Articulo reformado DOF 14-08-2001"

De esta manera se está en presencia de dos derechos de igual jerarquía que, deben ser aplicados para defensa, de quien es víctima de explotación laboral, así las cosas, los derechos humanos, como el derecho a la libertad de elección de trabajo, uno y otro son derechos positivos que, orientados a enaltecer y salvaguardar la persona humana deben actuar de consuno.

La acción que se acomete en la explotación laboral, enerva el derecho de libertad de trabajo, cuya sujeción tiene en la víctima, consecuencias en la propia acción de decidir, que se encuentra limitada y coartada por fuerzas que impactan negativamente, tanto intelectiva como físicamente y que impiden la capacidad de elegir, concretándose en el cumplimiento de imposiciones para la realización de trabajos, o actividades que de manera libre y en uso facultades mentales, no efectuaría, en tanto se pone en riesgo la propia vida, como su autoestima, por las consecuencias que su desobediencia pueden acarrearle. 
Con datos que actualizan e incluyen otras variables de las presentadas por la Organización Internacional del Trabajo y transcritas en el punto 5 del presente trabajo, se tiene sobre trabajo forzoso lo siguiente:

- “Casi 21 millones de personas son víctimas del trabajo forzoso: 11,4 millones de mujeres y niñas, y 9,5 millones de hombres y niños.

- Alrededor de 19 millones de víctimas son explotadas por individuos o empresas privadas y más de 2 millones por el Estado o grupos rebeldes.

- De aquellos que son explotados por individuos o empresas, 4,5 millones son víctimas de explotación sexual forzosa.

- El trabajo forzoso en la economía privada genera ganancias anuales ilegales de 150.000 millones de dólares por año.

- El trabajo doméstico, la agricultura, la construcción, la manufactura y el entretenimiento se encuentran entre los sectores más afectados.

- Los trabajadores migrantes y los pueblos indígenas son especialmente vulnerables al trabajo forzoso". ${ }^{14}$

De las cifras anteriores resulta relevante, el hecho de cómo, la autoría de la explotación laboral, se concentra en alto porcentaje en el sector privado, siendo significativo igualmente en cuanto al género, donde la femenina es la más afectada y los reglones económicos susceptibles son: el trabajo doméstico, la agricultura, la construcción, la manufactura y el entretenimiento, personas cuya sobrevivencia depende exclusivamente de su energía de trabajo, y en su mayoría cuenta con niveles educativos básicos o al grado extremo de ser analfabetas, sumándose a la estadística, poblaciones como la indígena que abandonan el lugar de origen, para procurarse "mejores" condiciones de vida, en calidad de migrante.

La Organización Internacional del Trabajo, expide el convenio 29, en materia de abolición de trabajo forzoso, en el año de 1930, ratificado por México el 12 de mayo de 1934, igualmente el convenio 105 de 1957 sobre la misma materia y ratificado por México el 1 junio de 1959, seguidamente la adopción del protocolo de 2014, relativo al convenio sobre trabajo forzoso, cuya entrada en vigor, el 9 de noviembre del 2016, y del cual hasta el momento solo ha sido ratificado por trece países, se pueden resaltar los siguientes aspectos:

- Todo Miembro deberá adoptar medidas eficaces en prevenir y eliminar todo trabajo forzoso.

- Proporcionar a las víctimas protección.

- Acceso a acciones jurídicas y de reparación apropiadas y eficaces.

- Sancionar a los autores del trabajo forzoso u obligatorio.

- Formular una política y un plan de acción nacionales a fin de lograr la supresión efectiva del trabajo forzoso, en consulta con las organizaciones de empleadores y trabajadores.

14 ORGANIZACIÓN INTERNACIONAL DEL TRABAJO, http://www.ilo.org/global/topics/forced-labour/ lang--es/index.htm, consultada en marzo 28 del 2017. 
Del mismo se resalta las acciones preventivas a realizar por los Estados Miembros que deben incluir:

- Educación e información focalizada en personas o grupos particularmente vulnerables con el propósito de evitar sean víctimas de trabajo forzoso u obligatorio.

- Educación e información a empleadores con el propósito de evitar resulten involucrados en prácticas de trabajo forzoso u obligatorio.

- Acciones que busquen garantizar:

- En el ámbito de la legislación nacional en materia de prevención de trabajo forzoso, como la legislación laboral en cuanto proceda, abarcará a todos los trabajadores, como a todos los sectores de la economía.

- Fortalecerá los servicios de inspección laboral y los demás aplicables según la legislación.

- Protección de las personas, en particular trabajadores migrantes.

- Apoyo a sectores públicos y privados a fin de realizar la prevención en materia de trabajo forzoso.

- Abordar la causa o causas que se presentan como generadoras del trabajo forzoso.

Para fortalecimiento de las acciones señaladas inmediatamente anteriores, cuando se evidencia la presencia de trabajo forzoso, los Estados Miembros deberán:

- Identificar, liberar, y proteger a las víctimas de trabajo forzoso, orientados a la recuperación, readaptación y cualquier forma de asistencia o apoyo.

Del mismo instrumento se desprende que la situación de trabajo forzado, puede conllevar conductas, como situaciones jurídicas que les pueda acarrear acciones jurídicas, en tal virtud priva la víctima de trabajo forzoso, razón por la cual, no será sujeto a enjuiciamiento por su situación o conductas en las que hubiese sido comprometido.

Resulta fundamental el ejercicio que en materia de cooperación los Estados Miembros, deben desplegar para prevenir toda forma de trabajo forzosa u obligatoria.

\section{CONCLUSIONES}

Primera: las expresiones de las sociedades contemporáneas tan cercanas a la tecnología, pero tan lejanas de la persona humana, han contribuido de manera importante a modificar y sustituir patrones de conductas, tendientes a valorar en mayor grado la forma que el fondo, el capital que la persona, desvalorización que debilita en el más alto grado la estructura de una sociedad, pero favorece conductas atentatorias en cuanto el ser humano es utilizado como instrumento para fines abyectos. En este sentido la explotación laboral es la expresión más burda de la cosificación de la persona, cuya acción se presenta contra la naturaleza del ser humano y cuya ejecución pone en tela de juicio la función que las constituciones 
tiene en una organización política, la salvaguarda de los derechos humanos, la vida y honra y bienes de las personas.

Segundo: La conducta de trata de personas asume diversas modalidades y su práctica se encuentra establecida como delito, tal situación jurídica no debe ser óbice para considerar los aspectos de naturaleza laboral que, surgidos bajo la égida de una conducta abusiva, atentatoria de los derechos humanos, fácticamente configuran una relación de trabajo para desprender de ella, el conjunto de obligaciones que en condiciones normales un trabajador tendría, condenando al pago de salarios factibles adeudados y en consecuencia los aspectos concernientes a la seguridad social, fundamentales, para revertir en lo posible el tiempo sujeto a vejaciones, señalándose las contribuciones correspondientes, para abonar semanas cotizadas, necesarias para la obtención de derechos, los cuales como hipotéticamente se sugiere sean exigidos mediante una autoridad jurisdiccional especial que tramite en conjunto las dos causas.

\section{BIBLIOGRAFÍA}

APARISI MIRALLES, Angela, Ética y Deontología para Juristas, Edit. Porrúa, México, 2009.

Cámara de Diputados del Honorable Congreso de la Unión, http://www.diputados. gob.mx/LeyesBiblio/pdf/LGPSEDMTP.pdf, consultada el 23 de agosto del 2016.

CASILLAS RAMÍREZ, Rodolfo, "Conocimiento Social, Derechos Humanos y Trata de Personas en México", en, Análisis sobre la trata de personas, No. 14, Estudios judiciales TSJDF, México, 2014.

DE BUEN L. Néstor, Derecho del trabajo, T.I., vigésima primera edición, Edit. Porrúa, México, 2013.

DE LA CUEVA, Mario, El Nuevo Derecho del Trabajo Mexicano, T.I., $7^{\text {a }}$ edición, Edit. Porrúa, México, 1981.

LANDA, César, "Dignidad de la Persona Humana", Revista del IIJ, Cuestiones Constitucionales Revista Mexicana de Derecho Constitucional, No. 7, julio-diciembre 2002 en, https://revistas.juridicas.unam.mx/index.php/ cuestiones-constitucionales/article/view/5649/7378, consultada el 10 de noviembre del 2016.

Organización Internacional del Trabajo, "Los trabajadores migrantes no son una mercancía". La revista de la OIT, número especial de 2014, publicada por el Departamento de Comunicación e Información Pública de la Organización Internacional del Trabajo (OIT), Ginebra, 2014.

Organización Internacional del Trabajo, http://www.ilo.org/global/topics/forcedlabour/lang--es/index.htm, consultada en marzo 28 del 2017.

VELÁZQUEZ GALARZA, Denisse, "La trata de personas desde la perspectiva internacional", en Análisis sobre la trata de personas, No. 14, Estudios judiciales TSJDF, México, 2014. 